\title{
Differentiated thyroid cancer in childhood: a literature update
}

\author{
Olga Karapanou, ${ }^{1}$ Marinella Tzanela, ${ }^{1}$ Barbara Vlassopoulou, ${ }^{1}$ \\ Christina Kanaka-Gantenbein ${ }^{2}$
}

${ }^{1}$ Department of Endocrinology, Diabetes and Metabolism, "Evangelismos" Hospital, Athens, Greece; ${ }^{2}$ Division of Endocrinology, Metabolism and Diabetes, First Department of Pediatrics, "Aghia Sophia" Children's Hospital, Athens, Greece

\begin{abstract}
Differentiated thyroid cancer in childhood is rare. Apart from family history, radiation exposure is a major risk factor. Although its clinical course is quite aggressive with higher rates of lymph node and pulmonary metastases as compared to adults, the final outcome tends to be favorable with mortality rates less than $2 \%$. We herein review the clinical picture, genetic background response to treatment and recurrence rates of differentiated thyroid cancer in children and young adolescents are thoroughly reviewed and the main differences with adult differentiated thyroid cancer are highlighted.
\end{abstract}

Key words: Differentiated thyroid cancer, Mutations, Outcome, Radiation, Recurrence

\section{EPIDEMIOLOGY}

Differentiated thyroid cancer is quite rare in childhood with an annual incidence of 0.2 to 1 cases per million children. Its incidence increases after the age of 10 years and reaches a zenith in adolescence when it increases by 10 -fold. ${ }^{1}$ Specifically, the incidence rates increase from 0.43 (5-9 years) to 3.5 (10-14 years) and finally to 15.6 per million (15-19 years). ${ }^{2,3}$ Prepubertally the rates are equal between males and females, whereas in adolescence there is a female predominence with a female to male ratio between 1-2.5 and 6, making thyroid cancer the second most common malignancy in adolescent girls ${ }^{3-5}$ (Figure

Address for correspondence:

Olga Karapanou, Tel.: +30 2130338913, Fax: +30 2106606050,

E-mail: olgakarapanou@yahoo.com

Received: 06-01-2018, Accepted: 18-01-2018
1). In childhood, papillary thyroid cancer accounts for more than $90 \%$ of all cases ${ }^{6,7}$ and follicular for $5-10 \%$ of cases occurring at slightly older ages. ${ }^{1,5-8}$ Dominant histologic variants of papillary thyroid cancer in childhood are solid, follicular and diffuse

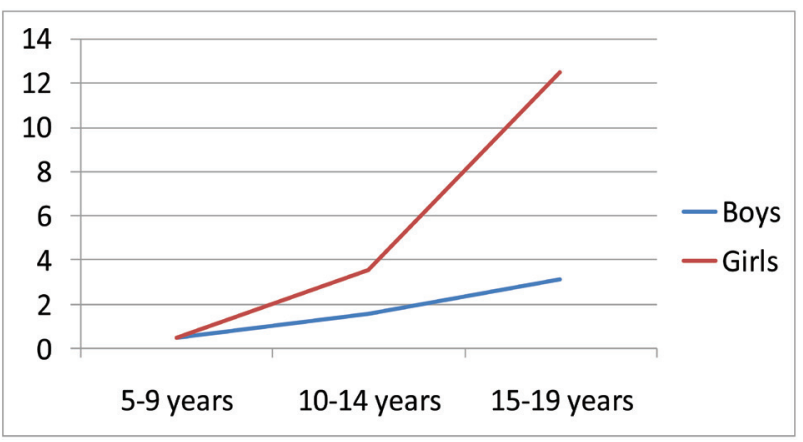

Figure 1. Incidence of thyroid cancer in childhood and adolescence. 
sclerosing. ${ }^{9}$ The incidence of NIFTP has not yet been widely investigated, although a recent study reported a rate of $1.9 \%$, i.e. less frequent than in adults. ${ }^{10}$ Medullary, poorly differentiated and anaplastic thyroid cancer are very rare in childhood.

\section{RISK FACTORS}

In approximately $5-10 \%$ of cases there is a family history of papillary thyroid carcinoma, comprising cases of adenomatous polyposis, DICER 1, PTEN hamartoma tumor syndrome, Carney complex or Cowden's disease. ${ }^{11}$ However the main risk factor for PTC is radiation exposure ${ }^{12,13}$ for children $<5$ years. ${ }^{14,15}$ In particular, approximately 5 years after the 1986 Chernobyl Nuclear Power Plant accident the incidence of papillary thyroid cancer in the contaminated areas of Belarus, Ukraine and the Russian Federation increased from less than 1 case per million per year before the accident to more than 90 cases per million per year and the exposed children continued to carry an increased risk into adult life. ${ }^{16}$ After 1996, the incidence declined progressively and after 2001 only sporadic cases, i.e. not through exposure to radiation, were reported in pediatric patients ( $<15$ years old). ${ }^{5,17-19}$ A non-significant increase in the prevalence of thyroid cancer was reported after the Fukushima Daiichi Nuclear Power Plant disaster where the radiation exposure was one tenth or less compared to the Chernobyl accident. ${ }^{19}$

\section{MUTATIONAL STATUS}

As shown in Table 1, a major difference between adult and pediatric PTC is that in children RET/PTC rearrangements are more common (30-70\% of PTC in childhood), while activating point mutations in the signal transducing pathway, such as RAS (NRAS being the most frequent) and $B R A F$ mutations, account for less than $10 \% .{ }^{20} P E T / P T C$ rearrangements occur after radiation exposure or internal contamination, this being the case of the Chernobyl accident. ${ }^{21}$ As radiation exposure induces DNA double-strand breaks, the RET gene and associated partners are highly vulnerable for recombination since they are juxtaposed in the nuclei of thyroid cells. To date, nearly 20 types of RET/PTC rearrangements have been identified. ${ }^{21,22}$ The overall prevalence of RET/PTC diverges between sporadic and radiation-exposed pediatric PTC carcinomas $(41 \%$ vs $58 \%$ respectively), ${ }^{23,24}$ with RET/PTC3 being associated with more aggressive tumors and RET/PTC1 with classic PTC. ${ }^{24,25}$ Due to interindividual variations in response to radiation, the role of genetic factors such as single nucleotide polymorphisms (SNPs) in the ATM and FOXE1 genes in radiation-induced PTC has been documented, suggesting that its etiology may involve a DNA repair pathway, a thyroid morphogenesis pathway and/or dysregulation of the differentiated state in the thyroid. ${ }^{26}$ In contrast to BRAF mutations, these RET/PTC rearrangements do not lead to genomic instability and dedifferentiation, which explains their better response to RAI and lower mortality rate. ${ }^{7,27}$ Several studies have demonstrated that sodium iodine symporter expression is greater than in adults. ${ }^{28,29}$ Moreover, a subsequent study showed that the expression of PDS, TPO and TSHR mRNA was higher in children compared to adults (22-59 years) and older patients ( $>60$ years) as well. ${ }^{30}$

\section{CLINICAL PRESENTATION}

Thyroid cancer in children usually presents as a solitary nodule..$^{31,32}$ The incidence of clinically palpable thyroid nodules in children is estimated to be around $1-1.5 \%$ and in adolescents up to $13 \% .{ }^{33}$ Nodules in children carry a greater risk of malignancy compared to those in adults $(22-26 \%$ versus $5-10 \%$ in most series). ${ }^{34-36}$ It is noteworthy that even autonomously functioning hot nodules carry a higher risk of malignancy compared to those in adults, i.e. up to $30 \%$ in

Table 1. Differences of differentiated thyroid cancer in childhood compared to adults.

\begin{tabular}{ll}
\hline Nodular disease & 4-fold higher risk for malignancy (22-26\% vs 5-10\%) \\
Genetic background & PET/PTC rearrangements $30-70 \%$ vs $10-20 \%$ and BRAF mutations $10 \%$ vs $40-50 \%$ \\
Clinical course & LMN metastases $80 \%$ vs $20-50 \%$ of adults and pulmonary metastases in $9-30 \%$ vs $2-9 \%$ of adults \\
Outcome & Better NIS expression and better response to RAI \\
\hline
\end{tabular}


children ${ }^{37}$ vs $3 \%$ in adults. ${ }^{38}$ Thyrotropin $>2.5 \mathrm{mIU} / \mathrm{L}$, suspicious ultrasonographic features i.e. microcalcifications or marked hypoechogenity, irregular margins, pathologic adenopathy or multinodular goiter were identified as independent predictors of malignancy together with FNA results. ${ }^{39}$ US characteristics and clinical context should be used for pathologic evaluation via fine-needle aspiration (FNA) ${ }^{40}$ rather than the size criterion alone, especially in a growing child whose thyroid may be half the size of an adult's. FNA is a useful modality in the evaluation of thyroid nodules in children, with $99 \%$ accuracy and overall sensitivity and specificity of $94 \%$ and $100 \%$, respectively. ${ }^{41}$ According to a recent study, the risk of malignancy, including papillary microcarcinoma, is $2 \%$ for benign aspirates, $26 \%$ for AUS, $57 \%$ for FN and $100 \%$ for suspicious or malignant aspirates, ${ }^{41}$ which is much higher than in adults. ${ }^{42}$ In the case of indeterminate cytology, given that data regarding molecular testing in children are insufficient they cannot be used in routine clinical practice. ${ }^{40}$ Thus, when cytology is indeterminate, surgery (lobectomy plus isthmusectomy) is favored over repeat FNA. ${ }^{40}$ Surgery is also a reasonable option for apparently benign growing nodules or those exceeding $4 \mathrm{~cm}$ and causing compressive symptoms. ${ }^{40}$

Compared to adult papillary carcinomas, the foci are often large, multifocal and bilateral. Multifocality and capsular invasion were significantly more frequent in patients less than 16 years of age. ${ }^{43}$ The clinical course is quite aggressive, with lymph node metastases in up to $80 \%$ of cases $^{44}$ vs $20-50 \%$ of adults ${ }^{45,46}$ and pulmonary metastases in approximately $9-30 \%$ of cases $^{47}$ vs $2-9 \%$ of adults ${ }^{48,49}$ (Table 1 ), while bone and central nervous system metastases are very rare. ${ }^{50-52}$ Children aged $<10$ years have higher rates of lymph node metastases compared to older children $(92.59 \%$ vs $71.43 \%) .{ }^{53}$ Distant metastases occur almost always in the lungs: they are diffuse, micronodular, not detected on standard chest X-rays and usually identified by I ${ }^{131}$-WBS. ${ }^{51,54-57}$

According to TNM classification, pediatric DTC without distant metastases is defined as stage I and in the presence of distant metastases as stage $\mathrm{II},{ }^{40}$ indicating a low risk of cancer-related death. Male gender, tumor stage and lymphadenopathy are risk factors for disease free survival in stage I pediatric DTC patients. ${ }^{56}$ According to the recent pediatric DTC guidelines, children with DTC should be categorized into three risk groups for recurrence: i) ATA pediatric low-risk patients are those with disease confined to the thyroid or with microscopic metastases to a small number of central lymph nodes (N1a), ii) ATA pediatric intermediate-risk patients are those with extensive N1a or minimal N1b disease and iii) ATA pediatric high-risk patients are those with extensive $\mathrm{N} 1 \mathrm{~b}$ and locally invasive disease (T4) with or without distant metastases. ${ }^{40}$

\section{TREATMENT}

The indicated surgical approach is total or neartotal thyroidectomy ${ }^{40}$ Recurrence rates are higher with lobectomy vs total thyroidectomy. ${ }^{44,49}$ Central neck dissection should be performed when there is evidence of central and/or lateral neck metastasis or gross extrathyroidal invasion. ${ }^{40}$ Routine prophylactic lateral neck dissection (levels III, IV, anterior V and II) is not recommended. However, lateral neck dissection should be performed on patients with cytologic evidence of metastases to the lateral neck. Measurement of Tg in the FNA washout can be considered if the cytological diagnosis is equivocal. RAI should be administered for treatment of locoregional/nodal disease not amenable to surgery and for the treatment of distant metastases. ${ }^{40}$ There is no benefit of RAI remnant ablation in pediatric patients with intrathyroidal disease and no lymph node disease. ${ }^{58}$ The postoperative activity of $\mathrm{I}^{131}$ administration is usually $37-74$ $\mathrm{MBq} / \mathrm{kg}$ (1-2 $\mathrm{mCi} / \mathrm{kg})$. An alternative to the fixed doses is a pretherapeutic dosimetry; $\mathrm{I}^{131}$ activities that are as high as safely administrable (AHASA) are at least $200 \mathrm{MBq} / \mathrm{kg}$ but in those patients with extensive pulmonary metastases a complete dosimetry including lung dose estimate is the only method to assess safe $\mathrm{I}^{131}$ activity. ${ }^{59}$ An abbreviated 2-week levothyroxine withdrawal protocol is indicated for preparation for radioiodine administration ${ }^{60}$ due to the more rapid T4 clearance and higher TSH to free T4 ratio in children. ${ }^{61}$ A hypothesis that may account for this difference is that kidney function is much better retained in children. Because of the expected survival time for young DTC patients, the benefits 
of RAI administration should be balanced against the risks, specifically, mainly the risk of second primary malignancy which at any site corresponds to 4.4 excess cases per 10,000 person-years at risk. ${ }^{62}$ The risk of development of a salivary malignancy is 1.7 excess cases per 10,000 person-years at risk, while the risk of developing leukemia, though slightly elevated, does not reach statistical significance. ${ }^{63}$ The risk of pulmonary fibrosis is $1 \%$ in children with diffuse pulmonary lesions, especially when the retained $\mathrm{I}^{131}$ activity exceeds $80 \mathrm{mCi} .{ }^{64}$ Permanent infertility does not occur in women with doses up to $300 \mathrm{mCi} \mathrm{I}^{131}$ and happen in less than $10 \%$ of men with this same dose. With doses of $800 \mathrm{mCi}$ or more, infertility would go up to $60 \%$ of women and more than $90 \%$ of men. ${ }^{65}$

There is no role for external beam radiation therapy in children because usually tumor foci in the neck concentrate radioiodine and thus subsequent $\mathrm{I}^{131}$ therapy remission is achieved. Following thyroidectomy, levothyroxine is given at higher doses per $\mathrm{kg}$ of body weight compared to adults in order that TSH may be decreased to $0.1 \mu \mathrm{U} / \mathrm{ml}$ and free $\mathrm{T} 3 /$ free $\mathrm{T} 4$ not exceed the above limit of normal range. The usual dose for children $<10$ years is $3-4 \mu \mathrm{g} / \mathrm{kg} /$ day, while adolescents 16-18 years require $2.4-2.8 \mu \mathrm{g} / \mathrm{kg} / \mathrm{day}{ }^{66}{ }^{6}$ In children who achieve complete remission, suppressive doses are no longer mandatory and the daily levothyroxine dose may be lowered in order to maintain TSH level in the low normal range (around $0.5 \mu \mathrm{U} / \mathrm{ml}$ ). ${ }^{40,67}$

\section{PROGNOSIS}

Pediatric thyroid carcinoma carries an excellent prognosis. In fact, despite its aggressive presentation in childhood, often with nodular involvement and pulmonary metastases, its prognosis is more favorable than in adults, ${ }^{68}$ showing long-term cause-specific mortality of less than $2 \% .{ }^{1,6,31,44,69}$ A systematic review demonstrated that following I ${ }^{131}$ treatment for pulmonary metastases complete remission is not achieved; however, disease-specific morbidity and mortality remain low $(2.68 \%),{ }^{47}$ while the 10 -year survival rate approaches $98 \%{ }^{2}$ The risk of recurrence should be estimated according to the ATA risk stratification, ${ }^{42}$ which is also valid for pediatric PTC. ${ }^{70}$ Children $<10$ years in contrast to adolescents present with large $\mathrm{e}^{71}$ multifocal tumors with a solid/follicular growth pat- tern, extrathyroidal extension, lymph node and lung metastases and have higher recurrence rates. ${ }^{70}$ The risk of recurrence correlates only with the extent of ETE and not with histologic subtype. ${ }^{72}$

Even in the case of radiation-induced thyroid cancer, an observational study of this high-risk pediatric population in the most contaminated regions near Chernobyl demonstrated that complete response [negative $\mathrm{I}^{131}$ whole-body scan and TSH-stimulated serum thyroglobulin $(\mathrm{Tg})<1 \mu \mathrm{g} / \mathrm{L}]$ was achieved in $64.2 \%$, nearly complete remission (complete response, except stimulated $\mathrm{Tg} 1-10 \mu \mathrm{g} / \mathrm{L}$ ) in $30.1 \%$ and partial remission $(\mathrm{Tg}>10 \mu \mathrm{g} / \mathrm{L}$, decrease from baseline in radioiodine uptake intensity in $>1$ focus, in tumor volume or in $\mathrm{Tg}$ ) in $4.8 \%{ }^{73}$

\section{FOLLOW-UP STRATEGIES}

Follow-up is accomplished by clinical examination, measurement of serum Tg levels, neck ultrasonography and whole body radioiodine diagnostic scans. $\mathrm{Tg}$ is a sensitive marker for residual or recurrent disease and should be measured along with $\mathrm{TgAb}$ since the presence of $\mathrm{TgAb}$ renders $\mathrm{Tg}$ results uninterpretable. ${ }^{74-76}$ The magnitude of TSH-stimulated Tg elevation in the absence of $\mathrm{TgAb}$ distinguishes between patients in remission and those with recurrence. If undetectable, there is a high probability of long-term remission and the patient is mainly monitored by TSH-suppressed Tg levels, TSH is maintained in the low-normal range and the intensity of follow-up is relaxed ${ }^{40} \mathrm{~A}$ low-level $\mathrm{TSH}$-stimulated $\mathrm{Tg}<10 \mathrm{ng} / \mathrm{ml}$ indicates persistent disease requiring serial TSH-supressed measurements and radiological imaging, although this value may decline over time without additional treatment. ${ }^{77} \mathrm{~A}$ clearly elevated TSH-stimulated $\mathrm{Tg}>10 \mathrm{ng} / \mathrm{ml}$ indicates structural disease necessitating localization and intervention. ${ }^{40}$ Cervical ultrasonography should be performed 6 months postoperatively, then annually for 5 years and thereafter for low-risk patients individualized according to the patient's risk of recurrence. ${ }^{40}$

In children previously treated with $\mathrm{I}^{131}$ a diagnostic RAI scan should be performed 12 months afterwards to confirm the absence of disease. If negative there is no need for a repeat diagnostic WBS. In contrast, for high-risk pediatric patients known to have RAIavid metastases, a diagnostic scan is beneficial and 
should be performed after at least 12 months of clinical follow-up and deferred even longer in children who continue to demonstrate a clinical response to previous treatment. ${ }^{78}$ Low-dose diagnostic $\mathrm{I}^{123}$ scans are preferred over $I^{131}$ scans due to decreased radiation exposure and avoidance of stunning. ${ }^{79}$ However, metastatic pulmonary foci may not always be visualized through these scans. ${ }^{79}$ Suspicious lymph nodes should be submitted to FNA and Tg measurement in the fluid aspirate. Surgery is favored for macroscopic $(>1 \mathrm{~cm})$ nodular disease, especially if located in a lymph node compartment not previously operated upon.$^{80}$ As previously mentioned, $\mathrm{I}^{131}$ is the treatment of choice for RAI-avid pulmonary metastases visualized with a diagnostic WBS. ${ }^{40}$

\section{REFERENCES}

1. Hogan AR, Zhuge Y, Perez EA, Koniaris LG, Lew JI, Sola JE, 2009 Pediatric thyroid carcinoma: incidence and outcomes in 1753 patients. J Surg Res 156: 167 172.

2. Vergamini LB, Frazier AL, Abrantes FL, Ribeiro KB, Rodriguez-Galindo C, 2014 Increase in the incidence of differentiated thyroid carcinoma in children, adolescents, and young adults: a population-based study. J Pediatr 164: 1481-1485.

3. Wu XC, Chen VW, Steele B, et al, 2003 Cancer incidence in adolescents and young adults in the United States, 1992-1997. J Adolesc Health 32: 405-415.

4. Ward E, DeSantis C, Robbins A, Kohler B, Jemal A, 2014 Childhood and adolescent cancer statistics, 2014. CA Cancer J Clin 64: 83-103.

5. Demidchik YE, Saenko VA, Yamashita S, 2007 Childhood thyroid cancer in Belarus, Russia, and Ukraine after Chernobyl and at present. Arq Bras Endocrinol Metabol 51: 748-762.

6. Harness JK, Thompson NW, McLeod MK, Pasieka JL, Fukuuchi A, 1992 Differentiated thyroid carcinoma in children and adolescents. World J Surg 16: 547-553.

7. Monaco SE, Pantanowitz L, Khalbuss WE, et al, 2012 Cytomorphological and molecular genetic findings in pediatric thyroid fine-needle aspiration. Cancer Cytopathol 120: 342-350.

8. Halac I, Zimmerman D, 2005 Thyroid nodules and cancers in children. Endocrinol Metab Clin North Am 34: 725-744.

9. Chan CM, Young J, Prager J, Travers S, 2017 Pediatric thyroid cancer. Adv Pediatr 64: 171-190.

10. Zhou H, Baloch ZW, Nayar R, et al, 2017 Noninvasive follicular thyroid neoplasm with papillary-like nuclear features (NIFTP): Implications for the risk of malignancy (ROM) in the Bethesda System for Reporting
Thyroid Cytopathology (TBSRTC). Cancer.

11. Khan A, Smellie J, Nutting C, Harrington K, Newbold K, 2010 Familial nonmedullary thyroid cancer: a review of the genetics. Thyroid 20: 795-801.

12. Tucker MA, Jones PH, Boice JD, Jr., et al, 1991 Therapeutic radiation at a young age is linked to secondary thyroid cancer. The Late Effects Study Group. Cancer Res 51: 2885-2888.

13. Sinnott B, Ron E, Schneider AB, 2010 Exposing the thyroid to radiation: a review of its current extent, risks, and implications. Endocr Rev 31: 756-773.

14. Cardis E, Hatch M, 2011 The Chernobyl accident--an epidemiological perspective. Clin Oncol (R Coll Radiol) 23: 251-260.

15. Schonfeld SJ, Lee C, Berrington de Gonzalez A, 2011 Medical exposure to radiation and thyroid cancer. Clin Oncol (R Coll Radiol) 23: 244-250.

16. Stsjazhko VA, Tsyb AF, Tronko ND, Souchkevitch G, Baverstock KF, 1995 Childhood thyroid cancer since accident at Chernobyl. BMJ 310: 801.

17. Williams D, 2008 Twenty years' experience with postChernobyl thyroid cancer. Best Pract Res Clin Endocrinol Metab 22: 1061-1073.

18. Tuttle RM, Vaisman F, Tronko MD, 2011 Clinical presentation and clinical outcomes in Chernobyl-related paediatric thyroid cancers: what do we know now? What can we expect in the future? Clin Oncol (R Coll Radiol) 23: 268-275.

19. Iwaku K, Noh JY, Sasaki E, et al, 2014 Changes in pediatric thyroid sonograms in or nearby the Kanto region before and after the accident at the Fukushima Daiichi nuclear power plant. Endocr J 61: 875-881.

20. Bongarzone I, Fugazzola L, Vigneri P, et al, 1996 Age-related activation of the tyrosine kinase receptor protooncogenes RET and NTRK1 in papillary thyroid carcinoma. J Clin Endocrinol Metab 81: 2006-2009.

21. Ricarte-Filho JC, Li S, Garcia-Rendueles ME, et al, 2013 Identification of kinase fusion oncogenes in postChernobyl radiation-induced thyroid cancers. J Clin Invest 123: 4935-4944.

22. Fusco A, Santoro M, 200720 years of RET/PTC in thyroid cancer: clinico-pathological correlations. Arq Bras Endocrinol Metabol 51: 731-735.

23. Cordioli MI, Moraes L, Cury AN, Cerutti JM, 2015 Are we really at the dawn of understanding sporadic pediatric thyroid carcinoma? Endocr Relat Cancer 22: R311-324.

24. Rabes HM, Demidchik EP, Sidorow JD, et al, 2000 Pattern of radiation-induced RET and NTRK1 rearrangements in 191 post-chernobyl papillary thyroid carcinomas: biological, phenotypic, and clinical implications. Clin Cancer Res 6: 1093-1103.

25. Elisei R, Romei C, Soldatenko PP, et al, 2000 New breakpoints in both the $\mathrm{H} 4$ and RET genes create a variant of PTC-1 in a post-Chernobyl papillary thyroid carcinoma. Clin Endocrinol (Oxf) 53: 131-136. 
26. Damiola F, Byrnes G, Moissonnier M, et al, 2014 Contribution of ATM and FOXE1 (TTF2) to risk of papillary thyroid carcinoma in Belarusian children exposed to radiation. Int J Cancer 134: 1659-1668.

27. Fenton CL, Lukes Y, Nicholson D, Dinauer CA, Francis GL, Tuttle RM, 2000 The ret/PTC mutations are common in sporadic papillary thyroid carcinoma of children and young adults. J Clin Endocrinol Metab 85: 1170-1175.

28. Patel A, Jhiang S, Dogra S, et al, 2002 Differentiated thyroid carcinoma that express sodium-iodide symporter have a lower risk of recurrence for children and adolescents. Pediatr Res 52: 737-744.

29. Faggiano A, Coulot J, Bellon N, et al, 2004 Age-dependent variation of follicular size and expression of iodine transporters in human thyroid tissue. J Nucl Med 45: 232-237.

30. Espadinha C, Santos JR, Sobrinho LG, Bugalho MJ, 2009 Expression of iodine metabolism genes in human thyroid tissues: evidence for age and BRAFV600E mutation dependency. Clin Endocrinol (Oxf) 70: 629-635.

31. Welch Dinauer CA, Tuttle RM, Robie DK, et al, 1998 Clinical features associated with metastasis and recurrence of differentiated thyroid cancer in children, adolescents and young adults. Clin Endocrinol (Oxf) 49: 619-628.

32. Grigsby PW, Gal-or A, Michalski JM, Doherty GM, 2002 Childhood and adolescent thyroid carcinoma. Cancer 95: 724-729.

33. Josefson J, Zimmerman D, 2008 Thyroid nodules and cancers in children. Pediatr Endocrinol Rev 6: 14-23.

34. Gupta A, Ly S, Castroneves LA, et al, 2013 A standardized assessment of thyroid nodules in children confirms higher cancer prevalence than in adults. J Clin Endocrinol Metab 98: 3238-3245.

35. Niedziela M, 2006 Pathogenesis, diagnosis and management of thyroid nodules in children. Endocr Relat Cancer 13: 427-453.

36. Gharib H, Papini E, Valcavi R, et al, 2006 American Association of Clinical Endocrinologists and Associazione Medici Endocrinologi medical guidelines for clinical practice for the diagnosis and management of thyroid nodules. Endocr Pract 12: 63-102.

37. Niedziela M, Breborowicz D, Trejster E, Korman E, 2002 Hot nodules in children and adolescents in western Poland from 1996 to 2000: clinical analysis of 31 patients. J Pediatr Endocrinol Metab 15: 823-830.

38. Dremier S, Coppee F, Delange F, Vassart G, Dumont JE, Van Sande J, 1996 Clinical review 84: Thyroid autonomy: mechanism and clinical effects. J Clin Endocrinol Metab 81: 4187-4193.

39. Papendieck P, Gruneiro-Papendieck L, Venara M, et al, 2015 Differentiated thyroid cancer in children: prevalence and predictors in a large cohort with thyroid nodules followed prospectively. J Pediatr 167: 199-201.

40. Francis GL, Waguespack SG, Bauer AJ, et al, 2015
Management guidelines for children with thyroid nodules and differentiated thyroid cancer. Thyroid 25: 716-759.

41. Partyka KL, Huang EC, Cramer HM, Chen S, Wu HH, 2016 Histologic and clinical follow-up of thyroid fineneedle aspirates in pediatric patients. Cancer Cytopathol 124: 467-471.

42. Haugen BR, Alexander EK, Bible KC, et al, 20162015 American Thyroid Association Management Guidelines for adult patients with thyroid nodules and differentiated thyroid cancer: The American Thyroid Association Guidelines Task Force on thyroid nodules and differentiated thyroid cancer. Thyroid 26: 1-133.

43. Dzodic R, Buta M, Markovic I, et al, 2014 Surgical management of well-differentiated thyroid carcinoma in children and adolescents: 33 years of experience of a single institution in Serbia. Endocr J 61: 1079-1086.

44. Hay ID, Gonzalez-Losada T, Reinalda MS, Honetschlager JA, Richards ML, Thompson GB, 2010 Long-term outcome in 215 children and adolescents with papillary thyroid cancer treated during 1940 through 2008. World J Surg 34: 1192-1202.

45. Zaydfudim V, Feurer ID, Griffin MR, Phay JE, 2008 The impact of lymph node involvement on survival in patients with papillary and follicular thyroid carcinoma. Surgery 144: 1070-1078.

46. Ahn BH, Kim JR, Jeong HC, Lee JS, Chang ES, Kim YH, 2015 Predictive factors of central lymph node metastasis in papillary thyroid carcinoma. Ann Surg Treat Res 88: 63-68 .

47. Pawelczak M, David R, Franklin B, Kessler M, Lam L, Shah B, 2010 Outcomes of children and adolescents with well-differentiated thyroid carcinoma and pulmonary metastases following (1)(3)(1)I treatment: a systematic review. Thyroid 20: 1095-1101.

48. Quaglia L, Cornaggia C, 2000 Experimental evidence of excited multicharged atomic fragments coming from laser-induced coulomb explosion of molecules. Phys Rev Lett 84: 4565-4568.

49. Handkiewicz-Junak D, Wloch J, Roskosz J, et al, 2007 Total thyroidectomy and adjuvant radioiodine treatment independently decrease locoregional recurrence risk in childhood and adolescent differentiated thyroid cancer. J Nucl Med 48: 879-888.

50. Newman KD, Black T, Heller G, et al, 1998 Differentiated thyroid cancer: determinants of disease progression in patients $<21$ years of age at diagnosis: a report from the Surgical Discipline Committee of the Children's Cancer Group. Ann Surg 227: 533-541.

51. Schlumberger M, De Vathaire F, Travagli JP, et al, 1987 Differentiated thyroid carcinoma in childhood: long term follow-up of 72 patients. J Clin Endocrinol Metab 65: 1088-1094.

52. Hay ID, 1987 Brain metastases from papillary thyroid carcinoma. Arch Intern Med 147: 607-611.

53. Mao XC, Yu WQ, Shang JB, Wang KJ, 2017 Clinical characteristics and treatment of thyroid cancer in 
children and adolescents: a retrospective analysis of 83 patients. J Zhejiang Univ Sci B 18: 430-436.

54. Vassilopoulou-Sellin R, Klein MJ, Smith TH, et al, 1993 Pulmonary metastases in children and young adults with differentiated thyroid cancer. Cancer 71: 1348-1352.

55. O'Gorman CS, Hamilton J, Rachmiel M, Gupta A, Ngan BY, Daneman D, 2010 Thyroid cancer in childhood: a retrospective review of childhood course. Thyroid 20: 375-380.

56. Wada N, Sugino K, Mimura T, et al, 2009 Treatment strategy of papillary thyroid carcinoma in children and adolescents: clinical significance of the initial nodal manifestation. Ann Surg Oncol 16: 3442-3449.

57. Giuffrida D, Scollo C, Pellegriti G, et al, 2002 Differentiated thyroid cancer in children and adolescents. $\mathrm{J}$ Endocrinol Invest 25: 18-24.

58. Lamartina L, Durante C, Filetti S, Cooper DS, 2015 Low-risk differentiated thyroid cancer and radioiodine remnant ablation: a systematic review of the literature. J Clin Endocrinol Metab 100: 1748-1761.

59. Verburg FA, Biko J, Diessl S, et al, 2011 I-131 activities as high as safely administrable (AHASA) for the treatment of children and adolescents with advanced differentiated thyroid cancer. J Clin Endocrinol Metab 96: E1268-1271.

60. Kuijt WJ, Huang SA, 2005 Children with differentiated thyroid cancer achieve adequate hyperthyrotropinemia within 14 days of levothyroxine withdrawal. J Clin Endocrinol Metab 90: 6123-6125.

61. Beckers C, 1997 Regulations and policies on radioiodine 131I therapy in Europe. Thyroid 7: 221-224.

62. Marti JL, Jain KS, Morris LG, 2015 Increased risk of second primary malignancy in pediatric and young adult patients treated with radioactive iodine for differentiated thyroid cancer. Thyroid 25: 681-687.

63. Gilabert M, Prebet T, 2012 Acute leukemia arising after radioiodine treatment for thyroid cancer. Haematologica 97: e28-29; author reply e30.

64. Rachmiel M, Charron M, Gupta A, et al, 2006 Evidencebased review of treatment and follow up of pediatric patients with differentiated thyroid carcinoma. J Pediatr Endocrinol Metab 19: 1377-1393.

65. Vini L, Hyer S, Al-Saadi A, Pratt B, Harmer C, 2002 Prognosis for fertility and ovarian function after treatment with radioiodine for thyroid cancer. Postgrad Med J 78: 92-93.

66. Burmeister LA, Goumaz MO, Mariash CN, Oppenheimer JH, 1992 Levothyroxine dose requirements for thyrotropin suppression in the treatment of differentiated thyroid cancer. J Clin Endocrinol Metab 75: 344-350.

67. Cooper DS, Specker B, Ho M, et al, 1998 Thyrotropin suppression and disease progression in patients with differentiated thyroid cancer: results from the National Thyroid Cancer Treatment Cooperative Registry. Thyroid 8 : $737-744$.
68. Gorlin JB, Sallan SE, 1990 Thyroid cancer in childhood. Endocrinol Metab Clin North Am 19: 649-662.

69. Popovtzer A, Shpitzer T, Bahar G, Feinmesser R, Segal K, 2006 Thyroid cancer in children: management and outcome experience of a referral center. Otolaryngol Head Neck Surg 135: 581-584.

70. Lazar L, Lebenthal Y, Segal K, et al, 2016 Pediatric thyroid cancer: postoperative classifications and response to initial therapy as prognostic factors. J Clin Endocrinol Metab 101: 1970-1979.

71. Zimmerman D, Hay ID, Gough IR, et al, 1988 Papillary thyroid carcinoma in children and adults: long-term follow-up of 1039 patients conservatively treated at one institution during three decades. Surgery 104: 1157-1166.

72. Balachandar S, La Quaglia M, Tuttle RM, Heller G, Ghossein RA, Sklar CA, 2016 Pediatric differentiated thyroid carcinoma of follicular cell origin: prognostic significance of histologic subtypes. Thyroid 26: 219-226.

73. Reiners C, Biko J, Haenscheid H, et al, 2013 Twenty-five years after chernobyl: outcome of radioiodine treatment in children and adolescents with very high-risk radiation-induced differentiated thyroid carcinoma. J Clin Endocrinol Metab 98: 3039-3048.

74. Spencer C, 2013 Commentary on: Implications of thyroglobulin antibody positivity in patients with differentiated thyroid cancer: a clinical position statement. Thyroid 23: 1190-1192.

75. Verburg FA, Luster M, Cupini C, et al, 2013 Implications of thyroglobulin antibody positivity in patients with differentiated thyroid cancer: a clinical position statement. Thyroid 23: 1211-1225.

76. Spencer CA, 2011 Clinical review: Clinical utility of thyroglobulin antibody ( $\mathrm{TgAb}$ ) measurements for patients with differentiated thyroid cancers (DTC). J Clin Endocrinol Metab 96: 3615-3627.

77. Mazzaferri EL, Robbins RJ, Spencer CA, et al, 2003 A consensus report of the role of serum thyroglobulin as a monitoring method for low-risk patients with papillary thyroid carcinoma. J Clin Endocrinol Metab 88: 1433-1441.

78. Biko J, Reiners C, Kreissl MC, Verburg FA, Demidchik Y, Drozd V, 2011 Favourable course of disease after incomplete remission on (131)I therapy in children with pulmonary metastases of papillary thyroid carcinoma: 10 years follow-up. Eur J Nucl Med Mol Imaging 38: 651-655.

79. Schoelwer MJ, Zimmerman D, Shore RM, Josefson JL, 2015 The Use of ${ }^{123} \mathrm{I}$ in Diagnostic Radioactive Iodine Scans in Children with Differentiated Thyroid Carcinoma. Thyroid 25: 935-941.

80. Clayman GL, Agarwal G, Edeiken BS, Waguespack SG, Roberts DB, Sherman SI, 2011 Long-term outcome of comprehensive central compartment dissection in patients with recurrent/persistent papillary thyroid carcinoma. Thyroid 21: 1309-1316. 